\title{
The Evaluation on the Three Critical Models of Absorptive Capacity: A Case Study on Logistics Company in Korea
}

\author{
Sung Woo Cho \\ Department of Logistics, Kunsan National University, Gunsan, Jeonbuk, Republic of Korea \\ *Corresponding Author: swcho@kunsan.ac.kr
}

Copyright $(2014$ Horizon Research Publishing All rights reserved

\begin{abstract}
Knowledge transfer is regarded as a critical element for successful business. Cohen and Levinthal initially proposed the concept of absorptive capacity in 1989 . Absorptive capacity is the ability to transfer and exploit external knowledge and it has become one of the most critical theories for two decades. The main purpose of the study is to identify the most appropriate model of absorptive capacity via statistical analyses. The three major models of absorptive capacity will be examined through the three core reconceptualization papers performed by Cohen and Levinthal (1990), Zahra and George (2002), and Todorova and Durisin (2007) in order to highlight a need for greater clarity about the construct of absorptive capacity. As a result, model 3 proposed by Todorova and Durisin (2007) was the most reasonable in this study.
\end{abstract}

Keywords Absorptive Capacity, Logistics Company, Knowledge Transfer, EFA, CFA, SEM

\section{Introduction}

From the perspective of international business, knowledge management and learning between organizations are regarded as a fundamental factor in recent decades both in academia and in business aspect. A number of corporations believe that knowledge is a core capability in order to maintain the organizational competency.

Knowledge is able to be acquired in two ways such as generated by internal effort and received by external resource. A company's internal development of knowledge is sometimes not a sufficient option. Thus, it is an essential process to obtain various information from external sources achieving better performance, overcoming a competitive business circumstance, and strengthening firm's capacity. However, many companies and employees recognize that the transfer of knowledge across firms is sometimes not easy. We can understand these points based on the business practices of multinational corporations.

In Cohen and Levinthal's study (1989), the concept of absorptive capacity is initially defined. Absorptive capacity is the ability to transfer and exploit external knowledge and it has become one of the most critical theories around 20 years (Camison and Fores, 2010). The researcher has tried to explain the theoretical background of absorptive capacity during two decades. But the relationship between the elements of models is not clearly identified yet. Therefore, the main purpose of the study is to identify the most appropriate model of absorptive capacity via statistical analyses.

\section{Materials and Methods}

\subsection{Definition of Absorptive Capacity}

In spite of various studies, the concept of absorptive capacity is not clearly defined because of the ambiguous definition and components. To fill these gaps, the definitions of absorptive capacity and its components will be discussed based on literature review in more detail in this and next chapter. The three major models of absorptive capacity will be examined through the three core reconceptualization papers performed by Cohen and Levinthal (1990), Zahra and George (2002), and Todorova and Durisin (2007) in order to highlight a need for greater clarity about the construct of absorptive capacity.

In 1989, Cohen and Levinthal proposed the concept of absorptive capacity based on preceding studies. They defined the concept of absorptive capacity as the potential capability "to learn from external knowledge through processes of knowledge identification, assimilation, and exploitation" (Cho, 2013). They reestablished the first definition in their second research paper, conducted empirical analysis and published in 1990. In this paper, the authors considered a new perspective with a greater focus on the "cognitive aspects" in process of learning and 
innovation. Cohen and Levinthal (1990) argued that innovative capabilities could be accomplished through processes of the perception of new values, the assimilation of acquired values, and applying them. In addition, they identified that the cognitive basis for individual's absorptive capacity is influenced by prior related knowledge and diversity of background and then, discussed the factors which can affect absorptive capacity at the organizational level. The definition proposed by Cohen and Levinthal (1990) was just limited to the context of technological knowledge.

A few studies had been conducted to find out a new conceptualization of the construct for a considerable period of time. Lane and Lubatkin (1998) found the fact that most of previous studies on inter-organizational learning had mainly focused on absorptive capacity as a firm's ability "to recognize the value of new, external knowledge, assimilate it and apply it to commercial ends". They regarded this definition of the construct as much of unreasonable aspects because authors believed that a firm does not have an equal ability to learn from all other organizations. Therefore, Lane and Lubatkin reinterpreted the construct that Cohen and Levinthal introduced and then, they generated and tested a model of inter-organizational learning. This new construct was dominated as a learning "dyad-level" construct, "relative absorptive capacity". They put forth new views by switching the unit of analysis of their construct from the firm to the "student-teacher" pairing (the learning dyad). Lane and Lubatkin's (1998) main argument was clearly stated in their research paper as follows. The capacity of a firm to learn from another company is jointly determined by the relative features of the student firm and the teacher firm. In other words, these characteristics are related to the similarity of both companies' (1) knowledge bases (2) organizational structures and compensation policies, and (3)dominant logics. The researchers argued that inter-organizational learning is positively correlated with the "similarity of the partners' basic knowledge, research centralization, compensation practices, lower management formalization, and research communities" (Lane and Lubatkin, 1998).

The most frequently cited paper on the constructs of absorptive capacity after Cohen and Levinthal's (1990) research is Zahra and George's (2002) study (Camison and Fores, 2010). According to Zahra and George (2002), absorptive capacity can be distinguished as two subsets such as a firm's potential capacity and realized capacity, if we consider the dynamic capability. The authors suggested that potential capacity consists of knowledge acquisition and assimilation capabilities, and realized capacity comprises knowledge transformation and exploitation. These two subsets work separately on, however perform interdependent roles. As identified by prior studies, firms cannot apply external knowledge without acquiring it. That is, some firms may be able to develop capability to acquire and assimilate external knowledge, however may not be able to transform and apply this knowledge. It means that the companies do not have the ability which can turn it into competitive advantage. Therefore, both components of absorptive capacity meet a necessary but these are insufficient condition to generate value for the firm.

Zahra and George (2002) carried out an empirical study in order to suggest the reconceptualization of absorptive capacity's construct. Their research raised important issues about the components, antecedents, contingencies, and outcomes of the construct. Hence, Todorova and Durisin (2007) proposed a new model by reflecting substantive changes. Researchers explored the components of absorptive capacity in Zahra and George's model and adopted the recognizing the value which is one of the components in Cohen and Levinthal's (1990) model. The step of transformation in a model of absorptive capacity based on Zahra and George (2002) is after the process of assimilation. However, in the model proposed by Todorova and Durisin (2007), components, assimilation and transformation, lie after acquisition and both processes are parallel to each other. An alternative process links to assimilation by multiple paths. In this respect, the distinction between potential absorptive capacity and realized absorptive capacity does not mean anything anymore. Authors considered and explained one of the contingency factors - power relationships - which influence both the valuing and the exploitation of new knowledge. Lastly, they proposed new feedback links in order to capture the dynamic aspects of the phenomenon.

\subsection{Dimension of Absorptive Capacity}

In this study, the dimensions of absorptive capacity are organized and explained based on Zahra and George (2002). The dimensions of absorptive capacity are comprised of acquisition, assimilation, transformation, and exploitation.

"Acquisition is a firm's ability to locate, identify, value, and acquire externally generated knowledge that has a decisive effect on its operations. Three characteristics (intensity, speed, and direction) can influence knowledge acquisition routines" (Cho et al., 2013). "The intensity and speed of a firm's efforts to identify and gather knowledge can be determined by the quality of a firm's acquisition capabilities". Kim (1997 a, b) clarified his position that a firm enables to achieve quickly indispensable abilities, if the company makes a great effort. Undoubtedly, it is hard to have a firm with the capability which is related to speed, because there are limits to shorten the easily learning cycle and to assemble together with each source that is needed to build absorptive capacity (Clark and Fujimoto, 1991). The last attribute, direction, is also critical to accomplish a high-quality of a firm's acquisition capabilities. "To utilize these attributes in their diversity and complexity, a firm's ability to import external knowledge or technologies might be maximized within its organization" (Cho et al., 2013).

"Assimilation capacity refers to a firm's capability to imbibe external knowledge. More specifically, this ability embodies the firm's routines and processes that allow the 
new information or knowledge acquired to be analyzed, processed, interpreted, understood, internalized and classified (Kim, 1997a, b; Szulanski, 1996). Ideas and discoveries that lie beyond a firm's search zone can be ignored because the firm cannot easily perceive them (Cyert and March, 1992; Rosenkopt and Nerkar, 2001)" (Cho et al., 2013). Externally acquired knowledge may include heuristics and is also context specific, which often prevents outsiders from understanding or replicating this knowledge (Szulanski, 1996). If the value of knowledge relies on the existence of complementary assets that may not be available to the recipient firm, it is not easy to do 'comprehension' (Teece, 1981). Comprehension, however, encourages knowledge assimilation that allows for firms to process and internalize externally generated knowledge.

"Transformation capacity refers to a firm's capability to develop and refine the internal routines that facilitate combining acquired knowledge and the newly acquired and assimilated knowledge. This is accomplished by adding or eliminating knowledge, or by interpreting and combining existing knowledge in a different, innovative way" (Cho et al., 2013). Transformation changes the attribute of knowledge via "bisociation" proposed by a psychologist Koestler in 1966 that happens when a situation or idea is perceived in "two self-consistent, but incompatible frames of reference" (Zahra and George, 2002). In addition, firms should realize that transformation capacity is to recognize two apparently incongruous sets of information and combine them to arrive at a new schema. Transformation capability, which was originated from the bisociation process, shapes the "entrepreneurial mindset" (McGrath and MacMillan, 2000). This capability provides new perspectives, promotes the recognition of opportunities, and helps to find new competencies which are able to generate activities. One thing that is certain is the fact that we are able to learn critical facts that have governed previous research on organizational transformation and strategic change, if we may understand the transformation component of absorptive capacity.

"Exploitation or application capacity denotes the organizational capacity based on routines that enables firms to incorporate acquired, assimilated and transformed knowledge into their operations and routines not only to refine, perfect, expand and leverage existing routines, processes, competences and knowledge, but also to create new operations, competences, routines, goods and organizational forms. As previously mentioned, definition of absorptive capacity suggested by Cohen and Levinthal (1990) highlights the application of knowledge. Organization sometimes can exploit knowledge by chance, without systematic routines. Exploitation indicates an organization's capability to gather and integrate knowledge into its operations (Tiemessen et al., 1997)" (Cho et al., 2013). It needs a process to retrieve knowledge that has been produced and internalized for utilization (Lyles and Schwenk, 1992). The constant formation of new systems, processes, goods, knowledge, or new organizational forms are achieved by the consequence of organized application procedure (Spender, 1996). Exploitation is obvious, for instance, in new ventures that seize knowledge from their market, competition, and customers. "Similarly, successfully established companies are likely to establish routines that target and deploy their knowledge to enhance existing initiatives or encourage new initiatives within a firm" (Rumelt, 1987).

\section{The Core Models of Absorptive Capacity}

The above examination illustrates the four dimensions of absorptive capacity based on Zahra and George's (2002) research. Now the three models of absorptive capacity, Cohen \&Levinthal (1990); Zahra \& George (2002); and Todorova\&Durisin (2007), will be illustrated and explained.

Cohen and Levinthal $(1989,1990)$ proposed the concept of absorptive capacity construct to name the ability of the firm to innovate and, therefore, to be dynamic. Absorptive capacity is composed of the capabilities to recognize the value of new knowledge, to assimilate it, and to apply it to commercial ends as discussed in the previous chapter. Absorptive capacity is influenced by the prior knowledge and knowledge source. It is conditioned on the appropriability regimes, and it has a decisive effect on the innovative performance of the firm. $<$ Figure $1>$ illustrates the antecedents, components, contingencies, and outcomes of absorptive capacity introduced by Cohen and Levinthal (1990).

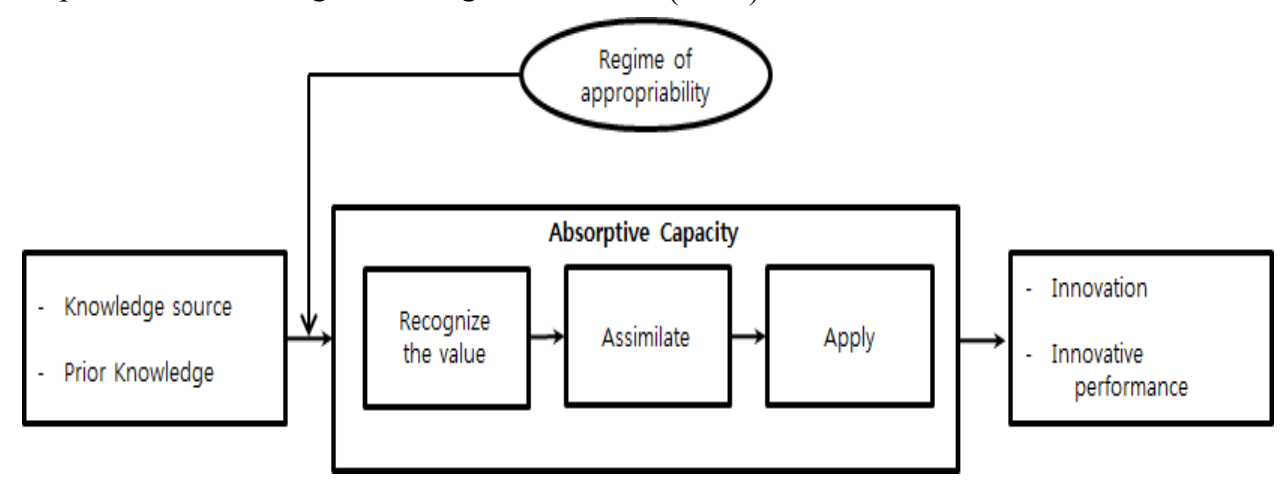

Figure 1. A model of absorptive capacity (Cohen and Levinthal, 1990) 


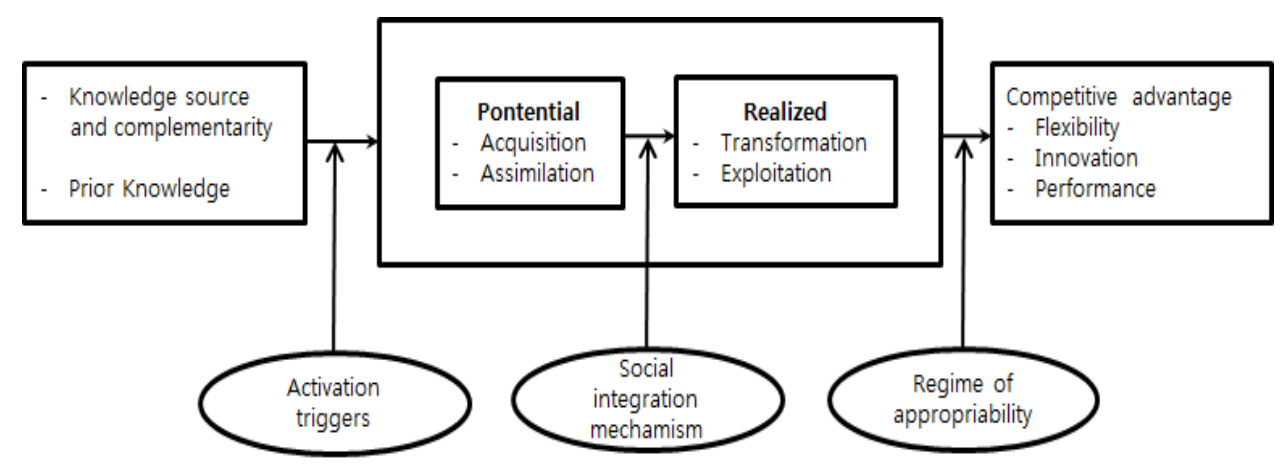

Figure 2. A model of absorptive capacity (Zahra and George, 2002)

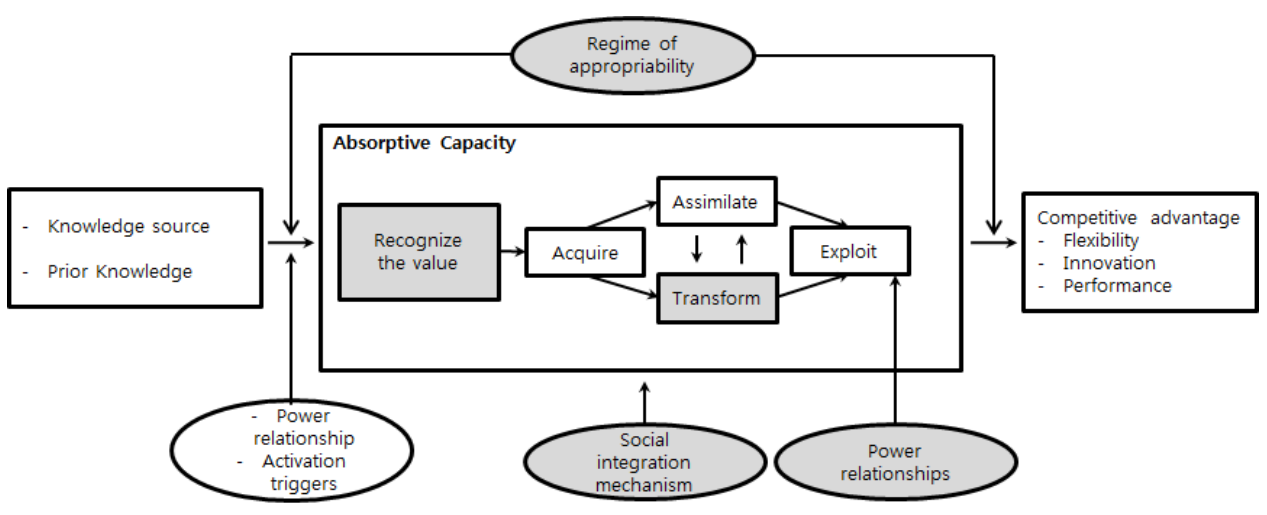

Figure 3. A model of absorptive capacity (Todorova and Durisin, 2007)

Zahra and George (2002) reviewed the literature on knowledge absorption and conceptualized absorptive capacity as a dynamic capability. Researchers insisted this conceptualization allows them to furnish a new model of the antecedents, components, contingencies, and outcomes of absorptive capacity (see Figure 2).

Making a comparison between the original model in $<$ Figure $1>$ and the new model in $<$ Figure $2>$, we are able to recognize the differences. Zahra and George (2002) replaced the component "recognizing the value" with "acquisition" and relocated the influence of the regimes of appropriability. Authors included the component of transformation, and the idea of activation triggers and social integration mechanisms. They separated absorptive capacity into "potential" absorptive capacity and "realized" absorptive capacity. Zahra and George's model is based on Cohen and Levinthal's study. Many scholars, however, have believed that Zahra and George do not build "systematically enough on Cohen and Levinthal's original contribution" (Todorova\&Durisin, 2007).

In 2007, Todorova and Durisin proposed a refined model of absorptive capacity based on the two prior studies (see Figure 3). Todorova and Levinthal stated the three substantive changes in their model. Firstly, they mainly referred to the literature of Zahra and George that is the components of absorptive capacity and reintroduced the original component in Cohen and Levinthal's (1990) construct. Author sitedcomponent, knowledge transformation is not a step after assimilation but the same position of assimilation. It represents an alternative process linked to assimilation by multiple paths. If we adopt a model proposed by Todorova and Durisin (2007), the difference between the two constructs-that is, potential absorptive capacity and realized absorptive capacity-does not exist anymore. The researchers introduce a new concept which is the efficiency of absorptive capacity instead of the constructs-potential absorptive capacity and realized absorptive capacity.

Secondly, Todorova and Durisin coped with contingency factors. Especially, the contingency factor of social integration should affect not only transformation but also the other components of absorptive capacity, if absorptive capacity is defined as a group of organizational routines. They strenuously insisted that "this contingency factor may influence the absorptive capacity not only in positive ways, as proposed in the Zahra and George's model, but also in negative ways" (Todorova and Durisin, 2007). They argued another contingency factor-namely, power relationshipswhich has an effect on the valuing and the exploitation of new knowledge.

Thirdly, the authors attached new feedback links in order to emphasize the dynamic aspects of the phenomenon. They evaluated that Zahra and George (2002) explained absorptive capacity as a dynamic capability that encourages organizational development and progress, but Zahra and George did not use "thinking in cycles typical of evolutionary approaches to management studies and, thus, fail to capture the dynamics and complexity of the phenomenon." 


\section{Statistical Analysis}

\subsection{Data Collection}

In the present study, a seven-point scale was employed to all questions in the questionnaire in order to retain uniformity. For instance, respondents were asked to choose one scale from 1 (strongly disagree) to 7 (strongly agree).

The sample of questionnaire for this study was drawn from the population of logistics companies. However, logistics industry can be classified various type of business, so several major business fields were categorized using some key papers and logistics magazines such as 'Korea Shipping Gazette', 'Maritimepress', and so on. The sample for survey was divided into six main categories: (1) maritime shipping that includes ocean carriers, port operation companies, and terminal operators; (2) roadway transport which is mainly called as trucking; (3) air transportation that includes airport facilities operators; (4) railroad transport except Korail because the organization is not a private corporation; (5) multimodal transport that covers freight forwarders except only documents handing firms; and (6) warehousing and cargo handling.

A on-line survey was launched using documents tool which was offered by Google without cost and it went without demur according to schedule for approximately 30 days. The number of 110 on-line samples was collected during approximately a month, but a delivery and collection questionnaire was performed with a on-line questionnaire at the same time after one month. The paper-based questionnaires were distributed the total number of 230 in the way of personal visit and 212 paper-based samples were collected since distribution for a month. The total samples were 322 acquired from a on-line survey and a delivery collection questionnaire and the number of 318 samples were used for statistical analyses except 4 samples that includes missing value.

Table 1. Construct and observed variables in structural model

\begin{tabular}{c|c|c}
\hline Category & Construct & Observed variable (indicator) \\
\hline \multirow{4}{*}{$\begin{array}{c}\text { Absorptive } \\
\text { Capacity }\end{array}$} & Acquisition & $\begin{array}{c}\text {-Openness towards the } \\
\text { environment } \\
\text {-R\&D cooperation }\end{array}$ \\
\cline { 2 - 3 } & Assimilation & $\begin{array}{c}\text {-Industrial benchmarking } \\
\text {-Attendance at training } \\
\text { courses and professional } \\
\text { events }\end{array}$ \\
\cline { 2 - 3 } & Transformation & $\begin{array}{c}\text {-Adaptation capacity } \\
\text {-Integration of R\&D }\end{array}$ \\
\cline { 2 - 3 } & Exploitation & $\begin{array}{c}\text {-New knowledge } \\
\text { exploitation }\end{array}$ \\
& $\begin{array}{c}\text {-Application of experience } \\
\text {-Technological } \\
\text { pro-activeness }\end{array}$ \\
\hline
\end{tabular}

\subsection{Methodology and Analysis}

The present research utilizes the PASW statistics 18 for exploratory factor analysis (EFA) and AMOS 18 for confirmatory factor analysis (CFA) and structural equation modeling (SEM). We have to reexamine the final observed variables that are confirmed through data screening, exploratory factor analysis (EFA), and confirmatory factor analysis (CFA) before the main analysis. For example, initially there were 19 measurements for absorptive capacity. The 19 observed variables were decreased to 13 measurements. The final version of constructs and observed variables purified by EFA and confirmed via CFA is presented in $<$ Table $1>$.

Table 2. EFA result of absorptive capacity

\begin{tabular}{|c|c|c|c|c|c|}
\hline \multicolumn{2}{|l|}{ Items } & 1 & 2 & 3 & 4 \\
\hline Exploitation & $\begin{array}{l}\text { exp11 } \\
\text { exp13 } \\
\text { exp15 } \\
\text { exp12 } \\
\text { exp16 }\end{array}$ & $\begin{array}{l}.820 \\
.769 \\
.750 \\
.745 \\
.620\end{array}$ & & & \\
\hline Acquisition & $\begin{array}{l}\text { aqs2 } \\
\text { aqs3 } \\
\text { aqs4 }\end{array}$ & & $\begin{array}{l}.763 \\
.730 \\
.573\end{array}$ & & \\
\hline Assimilation & $\begin{array}{l}\text { assm1 } \\
\text { assm2 } \\
\text { assm4 }\end{array}$ & & & $\begin{array}{l}.853 \\
.730 \\
.538\end{array}$ & \\
\hline Transformation & $\begin{array}{l}\operatorname{trns} 1 \\
\operatorname{trns} 2 \\
\operatorname{trns} 4\end{array}$ & & & & $\begin{array}{l}.834 \\
.661 \\
.653\end{array}$ \\
\hline Eigenval & & 3.442 & 2.290 & 1.910 & 1.854 \\
\hline$\%$ of Vari & & 24.583 & 16.354 & 13.642 & 13.245 \\
\hline Cumulativ & & 24.583 & 40.937 & 54.579 & 67.824 \\
\hline
\end{tabular}

Despite multivariate analysis techniques (e.g. multiple regression, factor analysis and SEM) are fairly strong tools for researchers, they should be processed to remove serious data missing, check outliers and normality, and make sure multicollinearity (Tabachnick and Fidell, 2007). Hair et al. (1998) stated that the data examination is an essential part of any multivariate analysis. We conducted the data examination procedure in order to get a satisfying result.

Exploratory factor analysis (EFA) was conducted to determine how and to what extent the observed variables are linked to their factors (acquisition, assimilation, transformation, and exploitation) in construct of absorptive capacity in this subsection. Principle components analysis with varimax rotation was introduced for identifying the minimal number of factors that underlie co-variation amongst the observed variables. In the present study, any factor loading smaller than 0.5 was deleted as recommended by Schwaiger and Opitz (2003). <Table 2> 
shows the final result of EFA of absorptive capacity.

CFA was conducted on default model that includes the total number of 14 observed variables and estimates were deducted from maximum likelihood method. All criteria were satisfied except trns1's estimate (trns1 Transformation: $0.247 \leq 0.4$ ). Therefore, the criteria of model fit indexes for default model, above all, will be identified and then, both a revised model which is excluded the trns 1 variable and the default model will be compared based on criteria of model fit summary. $<$ Table $3>$ shows the criteria of fit indexes both the default model and the new proposed model.

Table 3. SEM result of absorptive capacity

\begin{tabular}{c|c|c}
\hline Indexes & Default model & $\begin{array}{c}\text { New proposed model } \\
\text { (without trns1) }\end{array}$ \\
\hline CMIN/P & $144.514 / .000$ & $124.345 / .000$ \\
CMIN/DF & 2.035 & 2.108 \\
RMR & .077 & .077 \\
GFI & .937 & .940 \\
AGFI & .907 & .908 \\
NFI & .923 & .931 \\
IFI & .959 & .962 \\
TLI & .947 & .950 \\
CFI & .959 & .962 \\
RMSEA & .059 & .061 \\
\hline
\end{tabular}

All two models (a default model and a new proposed model) were not satisfied the criterion of $\mathrm{CMIN} / \mathrm{P}$ index $(p=0.000$, reasonable fit $p>0.005)$ and CMIN/DF index as well (value $<2$ good fit). However, six indexes such as GFI, AGFI, NFI, TLI, and CFI were wholly satisfied with criteria. Especially, values of the revised model without trns1 variable were higher than the default model, but in case of RMSEA index, the default model was more significant than the new model. Thus, the new proposed model will be applied to verify the best fitted model of three models of absorptive capacity suggested by Cohen and Levinthal (1990), Zahra and George (2002), Todorova and Durisin (2007).

Table 4. Assessment of reliability of construct of absorptive capacity

\begin{tabular}{c|c|c|c}
\hline $\begin{array}{c}\text { Constructs of } \\
\text { absorptive capacity }\end{array}$ & $\begin{array}{c}\text { Cronbach's } \\
\text { Alpha }\end{array}$ & $\begin{array}{c}\text { Construct } \\
\text { Reliability }\end{array}$ & $\begin{array}{c}\text { Variance } \\
\text { Extracted }\end{array}$ \\
\hline Acquisition & .812 & .810 & .589 \\
Assimilation & .700 & .708 & .447 \\
Transformation & .696 & .741 & .589 \\
Exploitation & .864 & .865 & .562 \\
\hline
\end{tabular}

As examined above, unidimensionality and convergent validity were satisfied. Reliability can be assessed by $\mathrm{R}^{2}$ (item reliability), Cronbach's alpha and construct reliability/variance extracted (scale reliability). <Table 4> describes each value of four constructs (acquisition, assimilation, transformation, and exploitation) about Cronbach's alpha, construct reliability, and variance extracted.

All the $\mathrm{R}^{2}$ (the squared multiple correlations) values are greater than 0.5 , thus item reliability is satisfied. The scale reliability is verified because the value of Cronbach's alpha for four factors are larger than 0.65 and all values of construct reliability are greater than 0.7 , in addition, all the values of variance extracted are greater than 0.4 .

\section{Conclusion}

The most suitable model among three leading models as mentioned earlier over and over will be identified using SEM. Three major models can be expressed as follows: (1) model1 means that Cohen and Levinthal (1990) initially established a basic concept of absorptive capacity; (2) model 2 reconstructed by Zahra and George (2002) are presented it as two constructs such as potential absorptive capacity (acquisition and assimilation) and realized absorptive capacity (transformation and exploitation); and (3) model3 redefined by Todorova and Durisin (2007) is a unique because of interaction between assimilation and transformation.

The important criteria of model fit indexes on three core models of absorptive capacity are clearly organized in $<$ Table 5>. As a result, the model fit indexes of modell and model 2 could not be acceptable compared with the criteria, implying that the estimated model is an adequately fitted model. In case of model3, all criteria were acceptable except indexed of RMR and AGFI because three models did not consider the point of the error covariance. If we allow for the error covariance, the model fit will increase remarkably. Thus, model 3 proposed by Todorova and Durisin (2007) was the most reasonable in this study.

Table 5. model fit summary on three key models

\begin{tabular}{c|c|c|c}
\hline Indexes & Model1 & Model2 & Model3 \\
\hline CMIN/P & $235.811 / .000$ & $326.922 / .000$ & $166.347 / .000$ \\
CMIN/DF & 3.803 & 5.108 & 2.772 \\
RMR & .112 & .127 & .097 \\
GFI & .890 & .838 & .921 \\
AGFI & .839 & .770 & .880 \\
NFI & .869 & .818 & .907 \\
IFI & .835 & .848 & .939 \\
TLI & .873 & .813 & .919 \\
CFI & .899 & .847 & .938 \\
RMSEA & .097 & .117 & .077 \\
\hline
\end{tabular}

Processes ensuring integration and learning are central to 
the dynamic capabilities of the firm (Winter, 2003). Absorptive capacity allows the firm to change to match the dynamics of the market (Cohen and Levinthal, 1990; Zahra and George, 2002). New knowledge cannot be assimilated. That is, in this case the cognitive structures of the individuals themselves must be transformed to adopt an idea or a situation that they cannot assimilate (Gleitman, 1995). Firms often fail to clearly distinguish between knowledge pieces that can successfully be altered to fit the prior knowledge structures from knowledge pieces that require the change of the organizational knowledge structures themselves. For instance, managers in the analog camera industry failed to understand changes in the industry initially because they repetitively tried to assimilate this knowledge through their old cognitive models instead of by transforming their cognitive structures (Tripsas and Gavetti, 2000).

Therefore, this study suggests that logistics firms should transform their knowledge structures when knowledge cannot be assimilated. Transformation represents an alternative process to assimilation. Managers in the logistics industry keep in their mind the fact that knowledge pieces may move not only from assimilation to transformation processes but also in the opposite direction. They have to recognize the importance of interaction between assimilation and transformation and examine closely the organizational knowledge structures and review carefully the processes between assimilation and transformation before the exploitation step.

\section{REFERENCES}

[1] Camison, C. and Fores, B., Knowledge absorptive capacity: New insight for its conceptualization and measurement, Journal of Business Research, Vol. 63, No. 7, pp. 707-715, 2010.

[2] Cho, S. W., Absorptive Capacity, Organizational Culture, and Logistics Performance: Focusing on the Logistics Company in Korea, Journal of International Trade and Commerce, Vol. 9, No. 2, pp. 129-150, 2013.

[3] Cho, S. W., Pak, M. S., Hur, Y. S. and Lee, J. S., The Relationship between Organizational Culture, Absorptive Capacity, and Performance of Korea's International Logistics Service Providers: Verification of the Mediation Effect, Journal of Korea Trade, Vol. 17, No. 3, pp. 55-75, 2013.

[4] Clark, K. B. and Fujimoto, T., Product development performance, Harvard Business School Press, Boston, 1991.

[5] Cohen, W. M. and Levinthal, D. A., Innovation and learning: The two faces of R\&D, Economic Journal, Vol. 99, pp. 569-596, 1989.

[6] Cohen, W. M. and Levinthal, D. A., Absorptive capacity: A new perspective on learning and innovation, Administrative Science Quarterly, Vol. 35, No. 1, pp. 128-152, 1990.
[7] Kim, L., The dynamics of Samsung's technological learning in semiconductors, California Management Review, Vol. 39, No. 3, pp. 86-100, 1997a.

[8] Kim, L., From imitation to innovation: The dynamics of Korea's technological learning, Harvard Business School Press, Boston, 1997b.

[9] Gleitman, H., Psychology, 4th Edition, Norton, New York, 1995.

[10] Hair, J. F., Anderson, R. E., Tatham, R. L. and Black, W. C., Multivariate data analysis, 5th Edition, Prentice-Hall, New Jersey, 1998.

[11] Lane, P. J. and Lubatkin, M., Relative absorptive capacity and interorganizational learning, Strategic Management Journal, Vol. 19, No. 8, pp. 461-477, 1998.

[12] Lyles, M. A. and Schwenk, C. R., Top management, strategy and organizational knowledge structures, Journal of Management Studies, Vol. 29, No. 2, pp. 155-174, 1992.

[13] McGrath, R. G. and MacMillan, I. C., The entrepreneurial mindset, Harvard Business School Press, Boston, 2000.

[14] Rumelt, R., Theory, strategy, and entrepreneurship, In Teece, D. J. (Ed.), "The competitive challenge: Strategies for industrial innovation and renewal", Ballinger, Boston, 1997.

[15] Schwaiger, M. and Opitz, O., Exploratory data analysis in empirical research, Springer-Verlag, Heidelberg, 2003.

[16] Spender, J. C., Making knowledge the basis of a dynamic theory of the firm, Strategic Management journal, Vol. 17, Winter special issue, pp. 45-62, 1996.

[17] Szulanski, G., Exploring internal stickiness: Impediments to the transfer of best practice within the firm, Strategic Management Journal, Vol. 17, No. 1, pp. 27-42, 1996.

[18] Tabachnick, B. G. and Fidell, L. S., "Using multivariate statistics", 5th Edition, Allyn and Bacon, Boston, 2007.

[19] Teece, D. J., The multinational enterprise: Market failure and market power considerations, Sloan Management Review, Vol. 18, pp. 3-17, 1981.

[20] Tiemessen, I., Lane, H. W., Crossan, M. and Inkpen, A. C., Knowledge management in international joint ventures, In Beamish, P. W. and Killing, J. P. (Eds.), "Cooperative strategies: North American perspective", New Lexington Press, San Francisco, 1997.

[21] Todorova, G. and Durisin, B., Absorptive capacity: valuing a reconceptualization, Academy of Management Review, Vol. 32, No. 3, pp. 774-786, 2007.

[22] Tripsas, M. and Gavetti, G., Capabilities, cognition and inertia: Evidence from digital imaging, Strategic Management Journal, Vol. 21, pp. 1147-1162, 2000.

[23] Winter, S. G., Understanding dynamic capabilities, Strategic Management Journal, Vol. 24, special issue, pp. 991-995, 2003.

[24] Zahra, S. A. and George, G., Absorptive capacity: A review, reconceptualization, and extension, Academy of Management Review, Vol. 27, No. 2, pp. 185-203, 2002. 